\title{
Methodical Principles of Evaluation of Competitive Ability of Construction Industry and Real Estate Development Companies
}

\author{
Svetlana Belyaeva ${ }^{1 *}$, Dmitrii Voronov ${ }^{2}$ and Sergei Erypalov ${ }^{3}$ \\ ${ }^{1}$ Voronezh State Technical University, 14, Moskovsky prospect, Voronezh, 394026, Russia \\ ${ }^{2}$ UMMC Technical University, Uspenskiy Ave. 3, VerkhnayaPyshma, Sverdlovsk region, 624091, \\ Russia \\ ${ }^{3}$ Ural Federal University named after the first President of Russia B.N. Yeltsin. 19 Mira st., \\ Ekaterinburg, 620002, Russia
}

\begin{abstract}
Based on systematization of methods and criteria of evaluation of competitive ability the present authors have substantiated the comparative principle of competitive ability. Selection algorithm of methodological instrumentarium for analytical competitiveness assessment was developed; a modification of a rating-based model of evaluation of competitive ability with the application of calculation and expert based methods have been presented as consequence. Obtained results in terms of time series provide representativity of arrays of information and significantly increase reliability of assessment. The method was tested by evaluating the competitive ability of several large real estate development companies and that of the construction industry.
\end{abstract}

\section{Introduction}

The continuing changes currently taking place in the construction industry (as well as in the economy of the country as a whole) that are related to Russia's accession to the World Trade Organization, imposition of sanctions, changes in the system of construction management, optimization of self-regulation in the industry and tightening of inspection standards related to technological and price components of real estate development and construction projects, lead the business leaders to refocus their attention on the issues of competitive ability and competitive strategies. This tendency is only natural owing to the local enterprises' need to keep a share of the market and competitive positions under the conditions when consumers' demand for high-quality products is shaping along with the necessity to comply with the high standards set forth for projects by experts of technological and price audit as well as with the requirements for energy efficiency and ecological safety of construction products, and when innovative products and processes are being constantly introduced.

*Corresponding author: belyaeva-sv@mail.ru 
Under these circumstances effective and stable company performance depends on its ability to choose a theoretically substantiated competitive approach and to implement vital competitive strengths in order to adapt to the constantly changing competitive landscape.

\section{Methods}

The influence of the above mentioned factors along with the process of managing the competitiveness and other processes of an enterprise form a certain level of competitive ability. It is worth noting that in contemporary economic science and practice there is no unified, generally accepted criterion of competitive ability. We suggest to systematize all existing methods and criteria of evaluation $[1,2,5]$ as follows: (fig.1).

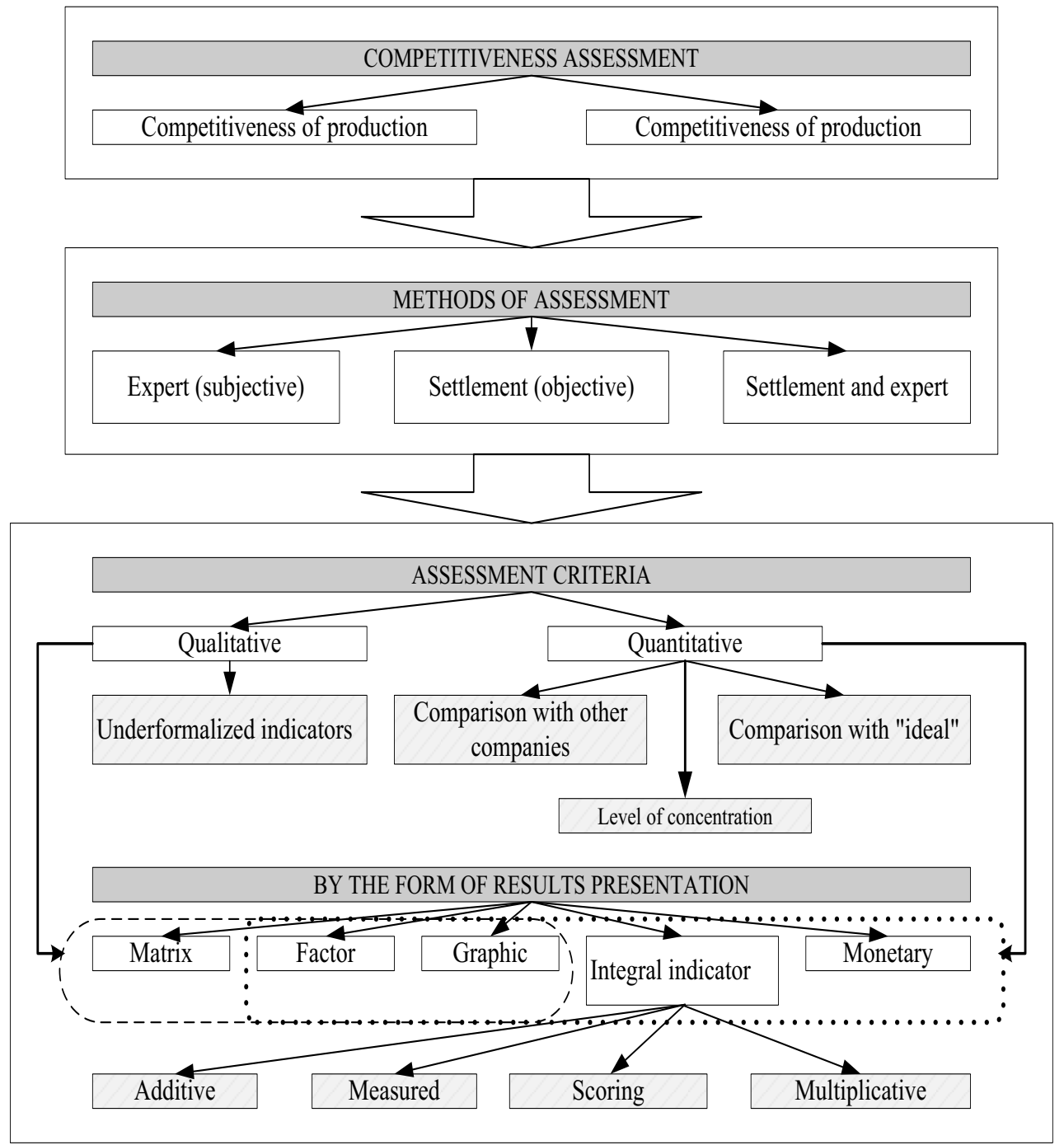

Fig. 1.Systematization of methods and criteria of evaluation of competitive ability

The majority of existing methods of evaluation of competitive ability, proceeding from the comparative principle of competitive ability and contesting essence of business competition, are based on comparing one or another result of company's performance with 
a number of other enterprises with corresponding business activity $[3,4,6]$. Therefore, a company (product, branch) rating compiled by certain criteria of competitive ability can be considered the main result of evaluation of competitive ability $[7,12]$.

Diversity of approaches, factors and criteria of evaluation of competitive ability results in a number of rating methods [8]. However the reported ratings often provide rather scanty tools for analyst as regards to drafting measures to enhance the competitive ability. This is due to the fact that the rating system does not provide an integral quantitative instrument for measuring the level of competitive ability, but allows to operate only with the enterprise's position in the ranking list. Thus the ratings at issue do not allow defining the differences between the two concerned companies in terms of quantity, which results in inability to identify and analyze the factors of shaping the competitive ability of the company in question and its dynamics. Therefore a lack of relevancy of data as well as imperfection of applied ranking method do not allow using the reported ratings to evaluate competitive ability of business entities. For this reason the important task is to perform an econometric analysis of the existing ratings of competitive ability, to build a model of these ratings, and also to build model ratings on the basis of the defined key competitiveness criteria. Building models helps to reveal significant factors on which the ratings are based. In fact, the results of analysis provide an answer to the question as to what does the concept of competitive ability imply.

In the absence of representative information on the ranking criteria calculation and expert based methods can be applied in order to establish the key criteria of competitive ability. In general terms the algorithm of analytical evaluation of level of competitive ability can be presented as follows (fig. 2).

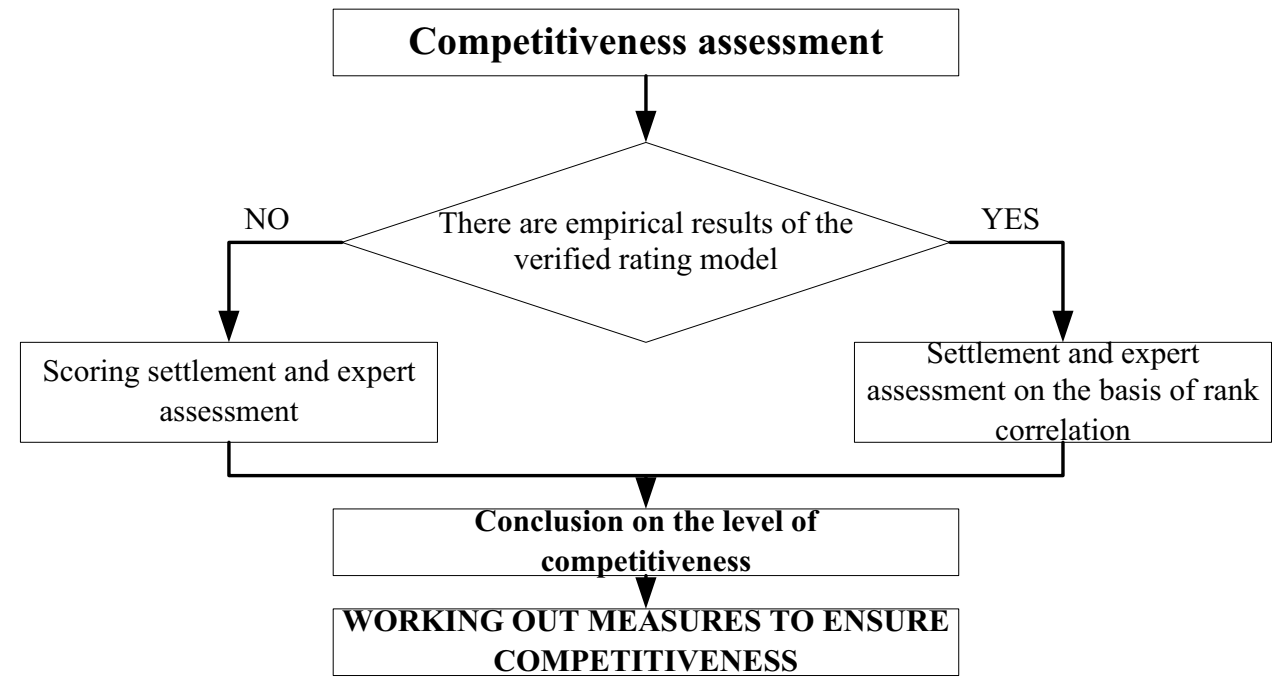

Fig. 2.Algorithm of selecting methodical instruments for analytical evaluation of competitive ability

If representative information on the dynamics of competitive ability ratings is available (as, for example, in the case of evaluating the global competitive ability of the WEF states) it is important to define the key parameters of the rating in order to elaborate the corrective actions. In this context, it is meaningful to draft a model rating using the models of multiple choice, based on the analysis of pair correlation of the rating evaluations, establishing the target function and defining the factor loadings. The target function represents an additive model of key criteria of competitive ability with due allowance for the factor loadings. The data on the factor loadings allows drawing conclusions as regards to the relative loading of 
a certain attribute in the structure of aresulting factor. In turn, the data on the factor loadings define the ranking of objects by each factor $[9,10]$.

In order to enhance the credibility of the calculation and expert based evaluation it is suggested to take the determination coefficient, i.e. correlation ratio square indicating the extent of the variation of the resulting attribute referable to variation of the factor attribute, as a numerical characteristic of the factor loading. Therefore the higher the determination coefficient, the stronger influence the factor in question exerts on the resulting attribute. In this case, the target function can be presented in additive form:

$$
F=a R_{1}+b R_{2}+\ldots+z R_{n}
$$

Where $a, b, z$ are measures of influence of determining factors on the resulting factor, or factor loading

values; $\mathrm{R}_{\mathrm{i}}$-optimum coefficients or ranks of the key criteria of competitive ability.

$$
\begin{aligned}
& R=\left[\begin{array}{cccc}
r_{11} & r_{12} & \cdots & r_{1 n} \\
r_{21} & r_{22} & \cdots & r_{2 n} \\
\cdots & \cdots & \cdots & \cdots \\
r_{m 1} & r_{m 2} & \cdots & r_{m n}
\end{array}\right] \quad \begin{array}{r}
\text { 1. Forming the matrix of ratings of competitive ability } \\
\text { where }
\end{array} \\
& \text { 2. Calculation of coefficient of rank correlation according to the Spearman's formula } \\
& p=1-\left(6 * \sum d_{i}^{2}\right) /\left(n^{3}-n\right) \\
& \text { where } \\
& \mathrm{d}_{\mathrm{i}}=\mathrm{x}_{\mathrm{i}}-\mathrm{y}_{\mathrm{i}} \\
& \mathrm{x}_{\mathrm{i}}, \mathrm{yi} \text { - ranks by attributes } \\
& \downarrow \quad \mathrm{n} \text { - number of objects. } \\
& \alpha_{i j}=p^{2} \quad \text { 3. Calculation of factor loadings (determination coefficients) } \\
& F=\sum_{i=1}^{n} \alpha_{i j} * r_{i j} \quad \text { 4. Construction of target function }
\end{aligned}
$$

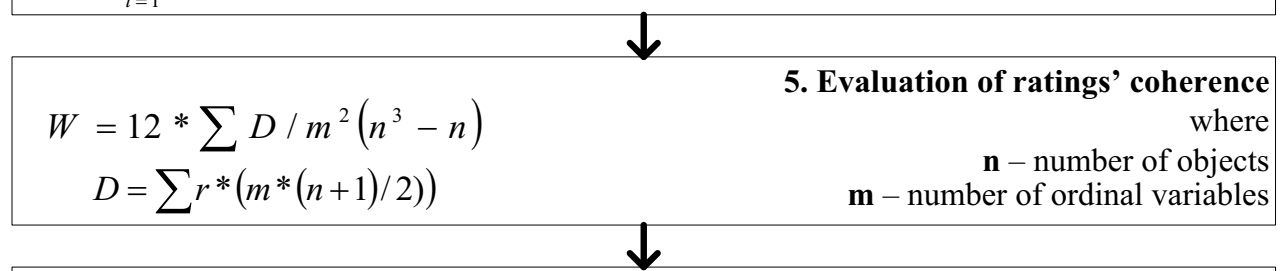

$$
\begin{aligned}
& \text { 6. Calculation of competitive ability according to the generalized ranking method } \\
& \text { 7. Constructing the rating of competitive ability } \\
& \text { 8. Working out the measures for securing competitive ability }
\end{aligned}
$$

Fig.3. Method of calculation and expert based evaluation of competitive ability based on rank correlation

In practice of evaluating the competitive ability, a number of objects is often defined not by two but rather by several rankings [11]. In such a case it is necessary to conduct an evaluation of a degree of coherence of the rating according to several different criteria and methods. Kendall's rank concordance (coherence) coefficient is used as such a measuring 
tool. In the process of calculation it could become clear that some of the assessed indexes are rather correlatable and, therefore, interdependent and replaceable. For this reason in these cases for purposes of optimization of calculation we deem it reasonable to modify the rating method by including only key criteria of competitive ability into the target function. Such a modification can be made by using the suggested method of calculation and expert based evaluation of competitive ability based on rank correlation (fig.3).

Therefore, different ratings of the largest Russian companies, published by the leading national media outlets specializing on economy, can be examined in view of applying the suggested method of calculation and expert based evaluation of competitive ability on the basis of rank correlation as an instrument of assessing the competitive ability of the enterprises. At the same time, we think that a comprehensive analysis of the level of competitive ability using a number of ratings is not efficient. The main reason for this is that the majority of existing ratings of enterprises are based on simple ranking of companies by total revenue (or by market value). However, neither operating efficiency (profitability), nor financial viability are taken into account. Therefore, positions of companies in such ratings and their actual competitive ability can differ essentially. For example, "Mechel", "SU-155", "Transaero" are listedamong the best Russian enterprises in the ratings at yearend 2014. High-profile bankruptcies of the mentioned business entities in the year 2015 are eloquent of the fact that the total revenue by no means always reflects the status of the company's competitive ability.

In this case, as in the case when representative information on the changes of the rating of competitive ability is unavailable, there is a need to develop a method that would allow drawing a more precise conclusion about the level of competitive ability and the relevant rating. We have worked out recommendations as regards to evaluating the level of competitive ability on the basis of calculation and expert based point-rating assessment, characterized by applying econometric methods and implemented by us in respect to analyzing the competitive ability of the industry sector (fig.4).

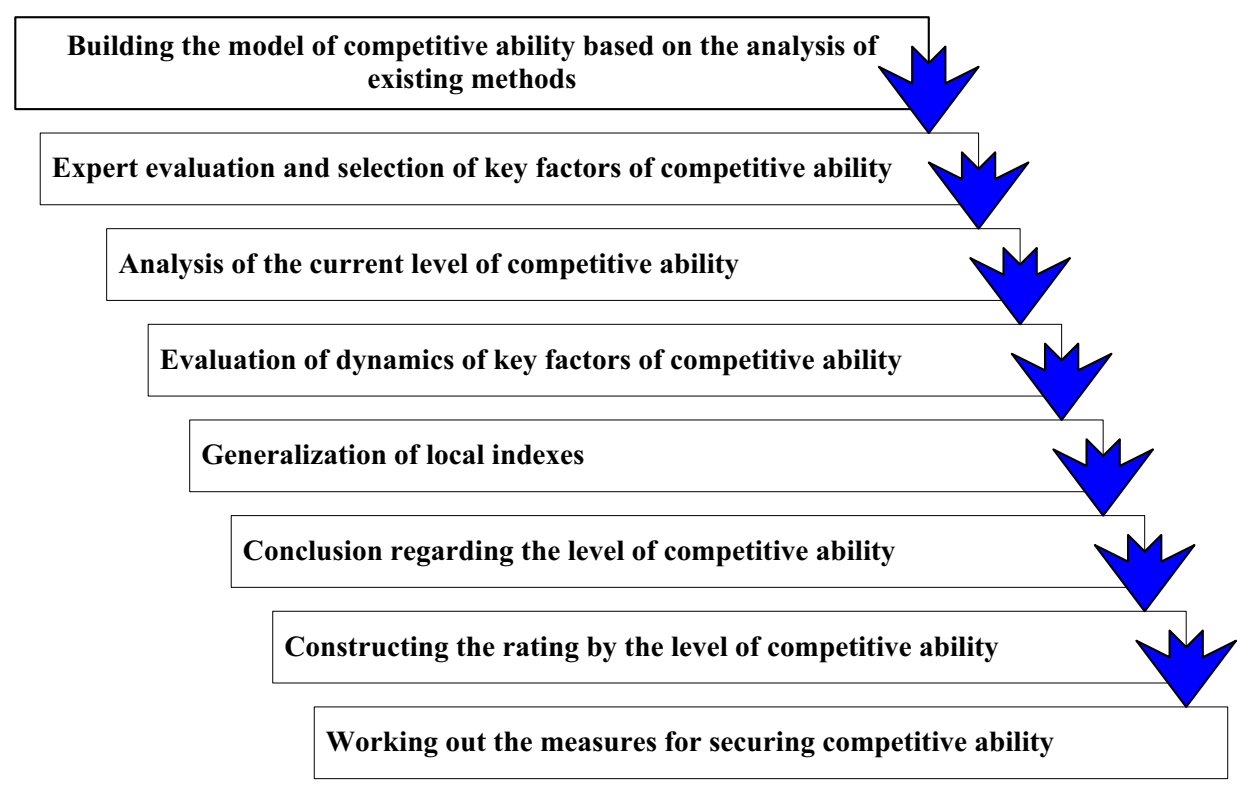

Fig.4.Methodical recommendations on evaluating the level of competitive ability on the basis of calculation and expert based point-rating assessment 


\section{Results}

Diversity of scientific approaches to determining the criteria of competitive ability of the industry sector [12] suggests setting up a problem of multi-criteria optimization. To solve the multi-criteria problem of optimization that was set up, it is necessary, first, to determine and structure the key parameters of competitive ability. We suggested selecting optimality criteria that make up competitive ability of the industry sector based on the expert evaluation [13]. Based on the outcome of the analysis of existing methodical approaches, three main clusters of criteria can be defined:

$$
K=f_{k(t)}(T, E, O)
$$

Wheref $f_{\mathrm{k}(\mathrm{t})}$ is the target function of competitive ability on criterion $\mathrm{k}$ at the moment of time $\mathrm{t}$; $\mathrm{T}$ - cluster of technological factors; $\mathrm{E}$ - cluster of economic factors; $\mathrm{O}$ - cluster of organizational factors.

Therefore, as a result of expert evaluation the following key criteria of competitive ability of the industry sector have been selected:

Table 1.Key criteria of competitive ability of the industry sector

\begin{tabular}{|l|l|l|l|l|l|l|l|l|}
\hline \multicolumn{2}{|l|}{$\begin{array}{l}\text { Technological factors' } \\
\text { indexes }\end{array}$} & \multicolumn{3}{|l|}{ Economic factors' indexes } & \multicolumn{2}{l|}{ Organizational factors' } \\
indexes
\end{tabular}

We suggest determining the share of influence of each of the indexes on the resulting level of competitive ability of the sector of industry by the following formula:

$$
D_{i}=\frac{\overline{B_{j i}}}{\sum_{i=1}^{n} \sum_{j=1}^{m} \overline{B_{i j}}}
$$

Where $D_{i}$ is the share of influence of $j$-index on the level of competitive ability; $B_{i j}-$ average score of $j$ - index of the i-group.

According to this principle, the overall score is made up by multiplying the loadings of ranks on hitting probabilities of these ranks and, thus, getting the probability loading of a criterion which is then multiplied on the criterion loading value; resulting values on each criterion are then summarized.

$$
U K=\sum_{i=1}^{4} \prod_{j=1}^{n} K_{i j} \cdot D_{i}
$$


Where UKis the level of competitive ability of the construction sector; $\mathrm{D}_{\mathrm{i}}$ - the share of influence of i-group of factors on the level of competitive ability; $K_{i j}$ - value of main $j$ index of i-group of factors of competitive ability of the industry sector.

According to the structure of GDP, key industry sectors, determining the economic stability of the specified types of economic activity of Russia, and consequentially, of the whole country, have been selected for analysis. The function of competitive ability of the industry sector with due account for expert evaluation and determining the shares of influence of criteria on the integral index of the level of competitive ability can be presented in the additive form:

$$
U K=0,1 B_{o k}+0,09 B_{i f}+0,09 B_{c r}+0,09 B_{t r}+0,09 B_{v v p}+0,09 B_{v r}+0,09 B_{d}+0,09 B_{g p}+0,1 B_{g k},
$$

Where UKis the level of competitive ability of the industry sector; $\mathrm{B}_{\mathrm{ok}}-$ score byte criterion of fixed capital investment of the industry sector; $B_{\text {if }}-$ score byte criterion of depreciation of fixed assets of the industry sector; $B_{c r}-$ score byte criterion of number of personnel of the industry sector; $B_{t r}$ - score byte criterion of rate of growth of the industry sector; $\mathrm{B}_{\mathrm{vvp}}$ - score byte criterion of GDP output in the industry sector; $\mathrm{B}_{\mathrm{vr}}-$ score byte criterion of level of demand of the sector of industry under the conditions of economic recession; $B_{d}-$ score byte criterion of share of profit-making organizations in the sector of industry; $\mathrm{B}_{\mathrm{gp}}$ - score byte criterion of level of state interference in the sector of industry; $\mathrm{B}_{\mathrm{gk}}$ - score by the criterion of volume of government-backed loans to the sector of industry.

The level of competitive ability of sectors of national economy is presented in fig. 5 .

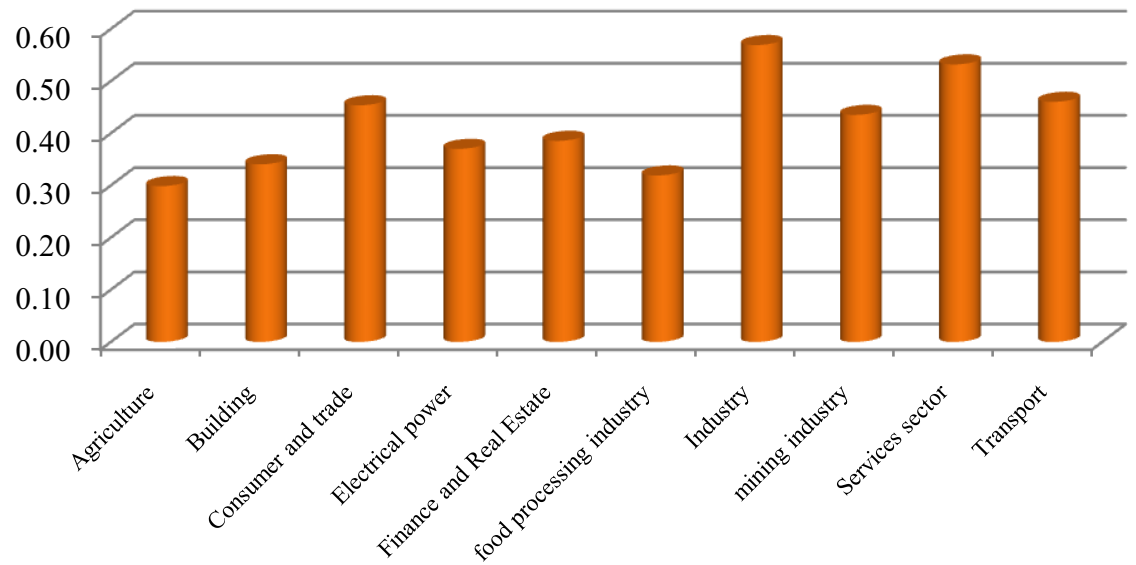

Fig.5.The level of competitive ability of sectors of national economy

Based on the calculations performed we can draw a conclusion that construction industry ranks 8-th in the Russia's national economy sectors rating in 2015. The results of the evaluation indicate the need to develop and implement measures of state regulation aimed at increasing efficiency and stability of operation in the construction sector.

\section{Discussion}

Key criteria that allow monitoring and preemptive actions aimed at preventing deterioration of competitiveness are substantiated in the suggested methodical recommendations.

Presented methodical recommendations ensure integration of quantitative and qualitative approaches to evaluating competitive ability and allow constructing a 
multifactor rating of sectors of national economy. It is suggested to evaluate the level of competitive ability of enterprises similarly to the abovementioned method, the only difference being that the rating correlation takes form of a dynamic model analyzing the change of key criteria of competitive ability of an enterprise not only with regard to the sampled competitor companies but also in comparison to the data of preceding time span. The sampling could include only one competitor company - in this case individual index of competitive ability of the company in question is defined compared to the selected competitor; several competitor companies - competitive ability of a company against a group of selected competitors is considered; or all competitor companies of the industry sector - in this case a sector index of competitive ability of an enterprise against all operating enterprises of the sector is "established". The following are considered among the key indexes of company's activity: operational efficiency (profitability of business activity), strategic positioning (dynamics of market share), and financial stability (liquidity) [14]. Breaking up the index of competitive ability of the enterprise by comparison objects in conjunction with the analysis of dynamics of these indexes allows for the conclusions as regards to what is the main reason of the existing level of competitive ability: high efficiency of business activity of the economic entity in question, low sampling efficiency etc.

\section{Conclusion}

It is obvious that without consideration for dynamics, even the most vital index value does not allow an ample insight into the analyzed process. At the other extreme, any information regarding the dynamics of an economic index makes a picture of a process many times more complete. In a methodological sense, the key principle of a dynamic approach is to perform calculations not only for the sample period but for the past period as well. Resulting statistical series guarantee representativeness of the body of data and boost the reliability of evaluation of competitive ability of enterprises.

Therefore, a periodical monitoring of dynamics of the level of competitive ability as well as that of the rating of competitiveness is required along with defining the key factors of dynamics and the corresponding "bottlenecks", proactive management of which could not only stabilize the tendencies of development and move to sustained growth of competitiveness, but also create new competitive advantages.

\section{References}

1. D.S. Voronov.Ural Federal University Bulletin. Economics and management series, 2, 24-40 (2015).

2. H.M. Gumba, S.V.Belyaeva, V.A.Vlasenko, S.S.Uvarova.Strategy of development of innovation activities of construction enterprises under conditions of business transformations, (VSUAE, Voronezh, 2016)

3. V.S. Kankhva. Economics and business, 5-2(46-1), 902-905 (2014)

4. E.V.Minko, A.E.Minko, V.P. Smirnov. Quality and competitive ability of products and processes, (Saint Petersbur, 2005)

5. E.V.Nezhnikova, R.V.Obuhov. Economics and business,2-1(67-1), 596-600, (2016)

6. E.V.Nezhnikova. Economics and business, 11-1(76-1), 1059-1062, (2016)

7. A.N.Asaul. Evaluation of competitive positions of business entities, $\mathrm{SPb}, 271,(2007)$

8. S.V.Belyaeva, V.S. Kanhva, L.V.Kochetova, S.S.Uvarova. Economics and business, 5, 453-456, (2016) 
9. D. Mendola, S. Volo. Tourism Management, 59, 541-553, (2017)

10.F. Candau, M. Goujon, J.-F. Hoarau, S. Rey. La Reunion Island. International Economics, 137, 1-21, (2014)

11. S. Wang. European Journal of Operational Research, 169, 329-331,(2006).

12. S. Gupta, N. K. Malhotra. Journal of Business Research.,69, 5671-5681, (2016)

13. T. W. Chung. The Asian Journal of Shipping and Logistics, 32, 257-264, (2016)

14. N.G.Bagautdinova,A.V.Sarkind, I.R.Gafurovc.. Procedia Economics and Finance, 14, 23-29, (2014) 